\title{
PUERPÉRIO DA VACA PELA ULTRA-SONOGRAFIA
}

\author{
COW POSTPARTUM BY ULTRASONOGRAPHY
}

Ivo Walter dos Santos ${ }^{1} \quad$ Jairo Pereira Neves ${ }^{2}$

\section{RESUMO}

Para caracterização ecográfica da involução uterina e reinício da atividade ovariana, o puerpério de 15 vacas da raça charolesa foi acompanhado pela ultra-sonografia a partir do $8^{\circ}$ dia, com intervalo de 3 dias, até $040^{\circ}$ dia pós-parto. Utilizou-se um aparelho de ultra-som Pie Medical Inc., mod. 450 com transdutor de $5 \mathrm{MHz}$, arranjo linear e uma impressora. A involução completa do útero foi detectada aos $28,12 \pm 1,55$ dias nas vacas com parto eutócico e aos $32,57 \pm 1,13$ dias nas vacas com parto distócico, e o conteúdo uterino não foi mais visualizado aos $18,87 \pm 1,12$ dias e $25,28 \pm 1,38$ dias, respectivamente, após o parto. O curso do puerpério foi testado por regressão linear e quadrática, quando observou-se uma diferença altamente significativa entre partos eutócico e distócico, na involução dos cornos uterinos ( $p<0,0001)$ e do cérvix $(p<0,01)$. No $10^{\circ}$ dia foram detectados folículos grandes nos ovários e no $13^{\circ}$ dia pós-parto, já ocorreu ovulação, porém, sem manifestação estral. O monitoramento da involução uterina e do conteúdo uterino durante o puerpério, assim como do reinício da atividade ovariana é viável através da ultrasonografia.

Palavras-chave: ultra-sonografia, vaca, puerpério.

\section{SUMMARY}

The aim of this study was to investigate uterus involution and ovarian activity by ultrasonography. The puerperium of fifteen charolais cows was observed from the $8^{\text {th }}$ to $40^{\text {th }}$ day, with interval of 3 days. A Pie Medical Inc. Scanner Mod. 450 with a $5 \mathrm{MHz}$ linear array transducer and a printer were used for ecographic purposes. The uterus complete involution, was detected on the $28.12 \pm 1.55$ days in the cows with normal parturition and on the $32.57 \pm 1.13$ days in the cows with dystocia and the lochia was not visualized on the $18.87 \pm 1.12$ days and $25.28 \pm 1.13$ day respectively postpartum. The puerperium period was tested by linear and quadratic regression. A high significance was observed, between normal and dystocic parturition on the uterine horn involution ( $p<0.0001)$ and the cervix $(p<0.01)$. On the $10^{\text {th }}$ day, great follicles was detected and on the $13^{\text {th }}$ day ovulation was observed without estrous manifestation. The correct monitoration of uterus involution, as well as the lochia and resumption of ovarian function, during the puerperium, is feasible through ultrasonography.

Key words: ultrasonography, cow, puerperium.

\footnotetext{
${ }^{1}$ Médico Veterinário, Professor, MS, Departamento de Patologia e Clínica Médica Veterinária, Centro de Ciências Rurais, URCAMP, 96400110, Bagé, RS.

${ }^{2}$ Médico Veterinário, Professor Titular, Doutor, Departamento de Clínica de Grandes Animais, Universidade Federal de Santa Maria, 97119 900, Santa Maria, RS, autor para correspondência.
} 


\section{INTRODUÇÃO}

Dada a importância do puerpério, para o futuro reprodutivo de uma vaca, GRUNERT \& ANDRESEN (1979) classificaram inicialmente o puerpério em períodos de delivramento das secundinas e puerpério propriamente dito. Este por sua vez, apresenta três fases assim caracterizadas: puerpério precoce, ocorre até o $10^{\circ}$ dia e é marcado pela redução significativa do tamanho do útero; puerpério clínico, ocorre até o $20^{\circ}$ dia, o útero já é semelhante ao de uma vaca não prenhe e iniciam-se as atividades cíclicas estrais; puerpério completo, com duração de 6 semanas quando o útero apresenta-se completamente involuído e o endométrio regenerado.

MOLLER (1970) observou que o crescimento folicular e a ovulação ocorrem mais cedo após o parto, do que é comumente suposto, detectando folículos dentro de 5 a 7 dias pós-parto, com a primeira ovulação por volta de 15 dias.

LA VOIE et al. (1981) observaram que o intervalo entre o parto e o primeiro estro foi de 20 dias em vacas que não amamentaram ad libitum. A ovulação ocorreu em todas as vacas no primeiro cio observado, porém, algumas ovularam com cio silencioso.

Segundo ROBERTS (1986) vacas que tiveram o parto auxiliado, em geral requerem 5 dias a mais para a involução completa do útero, em relação às vacas que tiveram parto eutócico.

MURPHY et al. (1990) demonstraram pela ultra-sonografia, que nas vacas de corte em amamentação, o desenvolvimento folicular e a formação do folículo dominante ocorreram logo após o parto, e a incidência de ovulação do primeiro folículo dominante é baixa, devido à falhas no processo de ovulação.

OKANO \& TOMIZUKA (1987) examinaram o útero de vacas no puerpério com transdutor de $5 \mathrm{MHz}$ e após, o útero foi removido cirurgicamente e acondicionado em recipiente com solução salina, para confirmar os resultados ecográficos. Concluíram que o endométrio pode ser visualizado claramente, porém o miométrio e perimétrio, ocasionalmente são identificados. A presença de lóquios no lume uterino foi observada até 15 dias pós-parto. Neste estágio, o útero pareceu estar edematoso, mostrando uma imagem ecográfica não ecogênica. A involução uterina se completou em aproximadamente 40 dias pós-parto.

PERRY et al. (1989) usaram um transdutor de $5 \mathrm{MHz}$ e observaram que o início do ciclo estral pósparto em vacas de corte, dá-se pela ovulação de um folículo grande mas, com baixa concentração de estradiol e, conseqüentemente, poucos sintomas de cio foram identificados, associados com a primeira ovulação.

Este estudo teve por finalidade avaliar ecograficamente a involução uterina e o reinício da atividade ovariana em vacas após o parto.

\section{MATERIAL E MÉTODOS}

Foram utilizadas 15 vacas da raça charolesa com idade de 5 a 10 anos, pertencentes à Cabanha Santo Izidro, localizada no município de Santa Maria, RS.

Para o estudo ecográfico foi utilizado um aparelho de ultra-som ${ }^{a}$ equipado com transdutor transretal de $5 \mathrm{MHz}$ e impressorab.

Devido ao grande volume do útero, somente foi possível realizar os exames a partir do $8^{\circ}$ dia pósparto. A partir desta data, tanto a involução uterina como a atividade ovariana, foram examinados com intervalo de 3 dias, até o 40 dia pós-parto.

Utilizou-se o terço do corno uterino, próximo ao corpo do útero para a realização das mensurações em corte transversal e as estruturas ovarianas (folículos e corpo lúteo) também foram consideradas.

Os partos foram assistidos e as vacas que receberam auxílio obstétrico foram tratadas com 4 tabletes de antibiótico ${ }^{c}$ no útero.

A involução uterina foi comparada em relação aos partos eutócicos e distócicos por regressão linear e quadrática.

\section{RESULTADOS}

Nas vacas que tiveram parto eutócico, foi observada a presença de líquidos no lume uterino

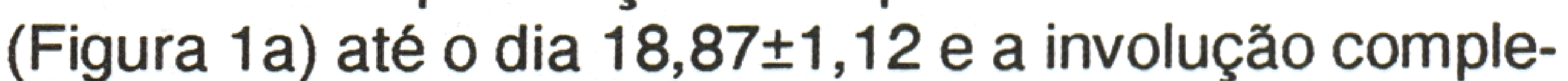
ta ocorreu aos 28,12 $\pm 1,55$ dias pós-parto (Figura 1b). Nas vacas que sofreram distocia, o conteúdo uterino foi observado até o dia $25,28 \pm 1,38$ e a involução total ocorreu aos $32,57 \pm 1,13$ dias pós-parto.

$\mathrm{Na}$ imagem ecográfica do corno uterino em corte transversal, o endométrio pode ser visualizado como uma estrutura de pouca ecogenicidade rodeando o conteúdo líquido não ecogênico, presente no lume uterino (Figura 2a). Quando este conteúdo deixou de ser percebido, o endométrio igualmente não o foi.

Após o término da involução uterina, a imagem obtida no corte transversal dos cornos, apresentou uma ecogenicidade heterogênea por toda sua extensão (Figura 1b). 


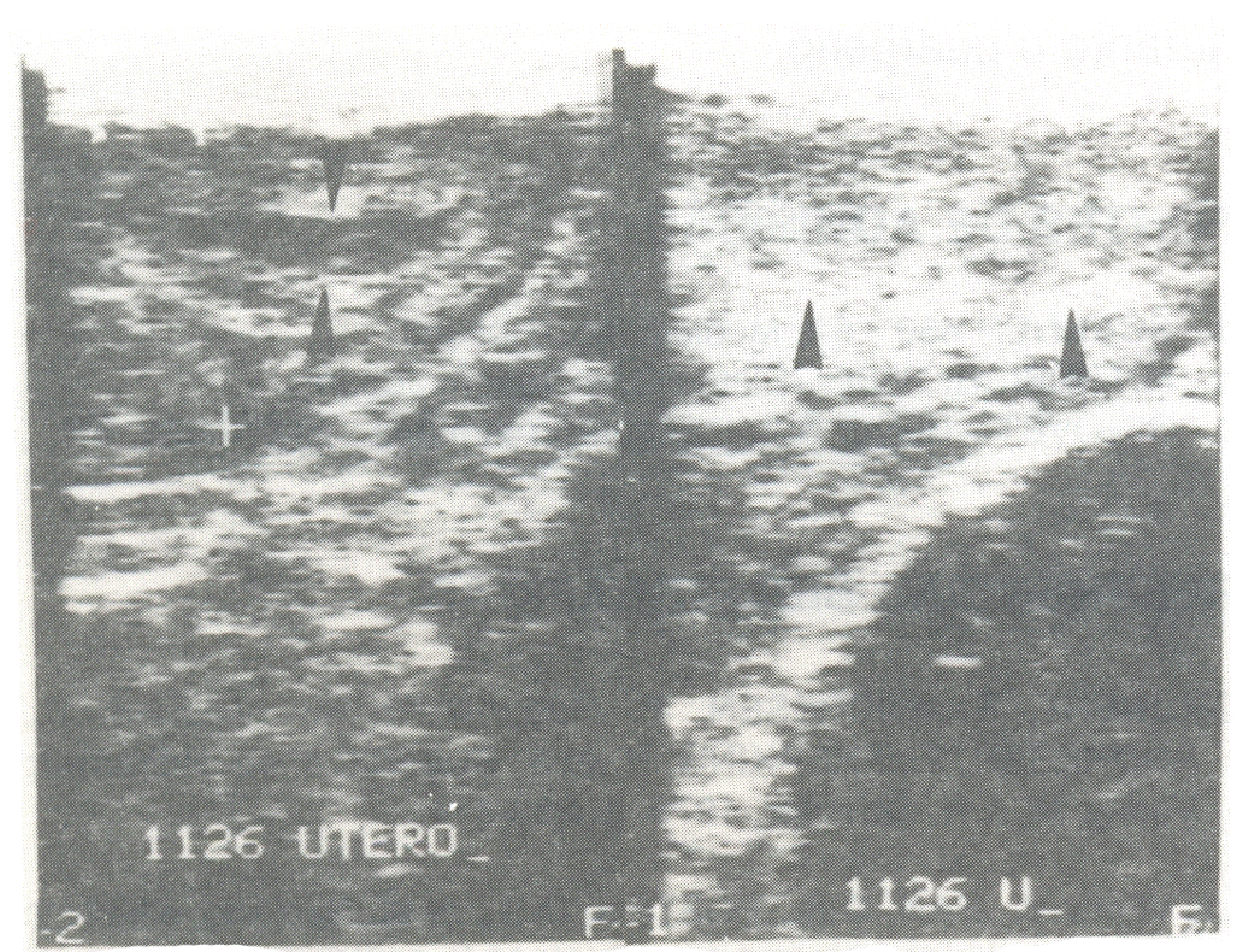

a

b
Figura 1 - Imagem ecográfica do corno uterino em corte transversal durante o puerpério: (a) 10 dia pós-parto com conteúdo líquido no lume; (b) involução completa 28 dias pós-parto (setas).

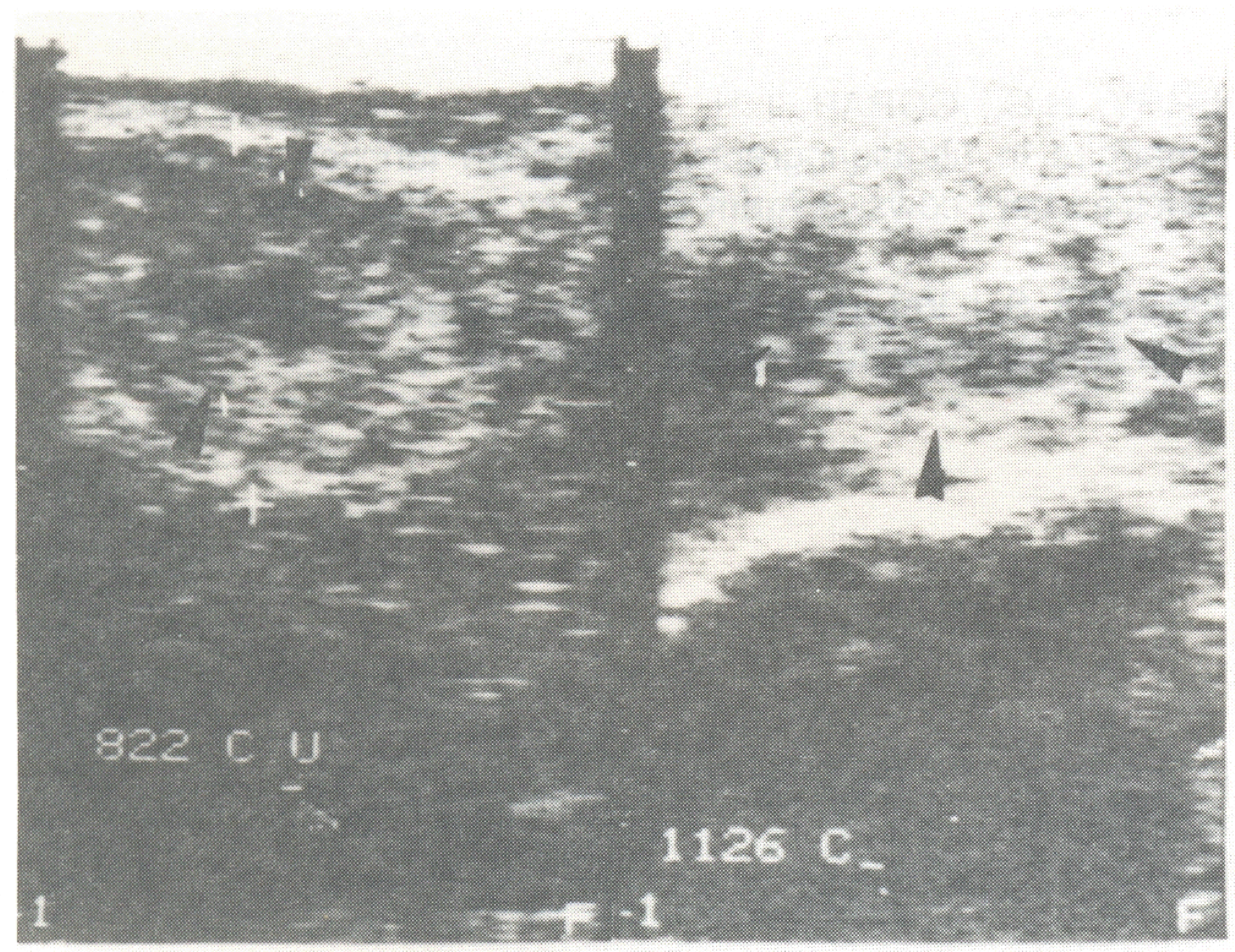

a

b

Figura 2 - Imagens ecográficas em corte transversal: (a) endométrio no puerpério; (b) colo uterino após a involução completa do purpério (setas).

O cérvix apresentou líquido na sua luz no mesmo período, correspondente, em que foi visualizado conteúdo no lume uterino.
Após a involução completa do útero, ainda foi possivel identificar a luz cervical em corte transversal pela ecografia, caracterizada como uma área de pouca ecogenicidade, medindo em média $5 \mathrm{~mm}$ de diâmetro no centro da imagem (Figura $2 b$ ).

A Figura 3 mostra que durante o puerpério, foi observada uma diferença significativa entre parto eutócico e distócico na duração do período de involução dos cornos uterinos $(p<0,0001)$ e cérvix $(p<0,01)$.

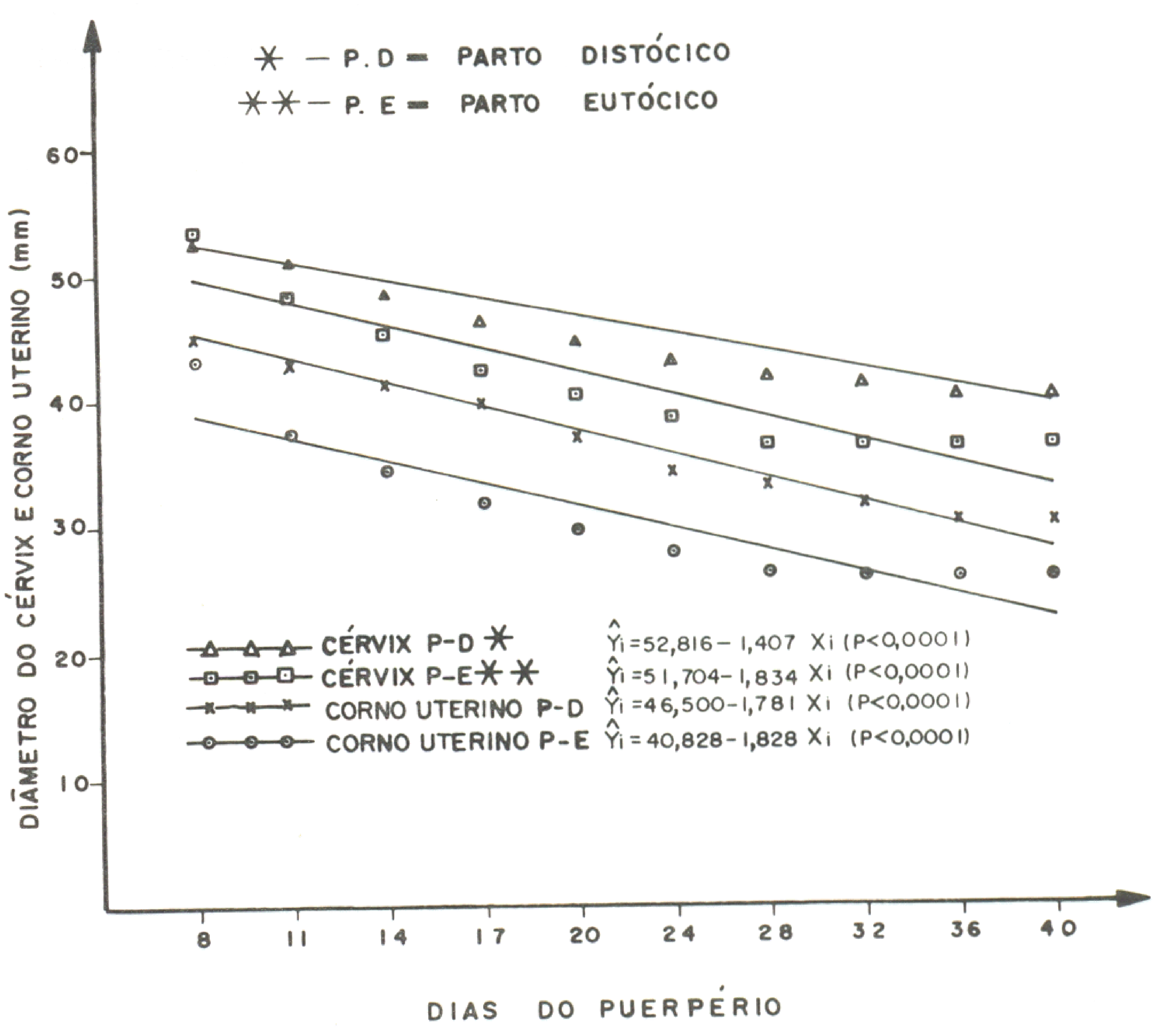

Figura 3 - Involução dos cornos uterinos e cérvix de vacas charolesas que pariram sem auxílio e com auxílio até 40 dias pós-parto.

Os diâmetros dos cornos uterinos e cérvix, após a involução completa do órgão, permaneceram maiores (Figura 3 ) nas vacas que tiveram parto distócico.

A atividade ovariana teve início logo após o parto, pois já no $10^{\circ}$ dia, foram detectados folículos grandes $(\geq 10 \mathrm{~mm})$, sendo que no $13^{\circ}$ dia, duas vacas apresentaram ovulação sem manifestação estral.

\section{DISCUSSÃO E CONCLUSÕES}

O acompanhamento da involução uterina através da ecografia, possibilitou a avaliação do diâmetro dos cornos uterinos e do cérvix. A luz uterina foi observada até o $19^{\circ}$ dia nas vacas com parto eutócico e até o $25^{\circ}$ dia naquelas com parto auxiliado. 
OKANO \& TOMIZUKA (1987) observaram lóquios até o $15^{\circ}$ dia. Supőe-se que esta diferença, seja devido às condições de parto.

A involução completa do útero ocorreu aos 28 dias nas vacas com parto eutócico e aos 32 dias naquelas com parto auxiliado. Esta diferença ocorreu, provavelmente, pela atonia uterina presente nos casos de distocia, conforme as observações de ROBERTS (1986).

Somente o endométrio pode ser identificado pela ultra-sonografia, concordando parcialmente com os resultados de OKANO \& TOMIZUKA (1987), os quais apenas ocasionalmente, detectaram o miométrio e o perimétrio, além do endométrio. Visualizaram ainda um edema de parede.

O exame ecográfico dos ovários após o parto, foi possível a partir do $10^{\circ}$ dia nas vacas com parto normal e $14^{\circ}$ dia nas vacas com parto auxiliado, portanto, na fase final do puerpério precoce, conforme a classificação de GRUNERT \& ANDRESEN (1979), devido à dificuldade de acesso pelo grande porte das vacas, associado ao grande volume do trato genital.

O crescimento folicular após o parto, já foi observado no primeiro exame (10 dias após o parto). Com 13 dias, duas vacas ovularam sem manifestar estro, o que também foi observado por MOLLER (1970) e LA VOIE (1981).

A duração do puerpério foi influenciada pelas características do parto, e o reinício da atividade ovariana pode ser detectada já nos primeiros dias do puerpério.

A ultra-sonografia, sendo mais um meio auxiliar de diagnóstico, foi de grande valia na avaliação da involução uterina, determinação da quantidade dos lóquios, bem como na avaliação da atividade ovariana durante o puerpério.

\section{FONTES DE AQUISIÇÃO}

a - SCANNER 450 - Pie Medical Inc., Holland.

b - MITSUBISHI P66E - Eletric Corporation, Japan.

c - GINOVET - Univet S.A. Indústria Veterinária - São Paulo, SP.

\section{REFERÊNCIAS BIBLIOGRÁFICAS}

GRUNERT, E. ANDRESEN, P. Geburtshilfe. In: AHLERS, P., ANDRESEN, P., FRERKING, H. et al. Buiatrik, 3. ed. Hannover: Verlag M. \& H. Schaper, 1979. p. 259-314.

LA VOIE, V., HAN, D.K., FOSTER, D.B., et al. Suckling effect on estrous and blood plasma progesterone in postpartum beef cows. J Anim Sci, v. 52, n. 4, p. 802-814, 1981.

MOLLER, K. A review of uterine involution and ovarian activity during the postparturient period in the cow. New Zealand Veterinary Journal, v. 5, n. 18, p. 83-90, 1970.

MURPHY, M.G., BOLAND, M.P., ROCHE, J.F. Pattern of follicular growth and resumption of ovarian activity in post-partum beef sucker cows. J Reprod Fert, n. 90, p. 523-533, 1990.

OKANO, A., TOMIZUKA, T. Ultrasonic observation of postpartum uterine involution in the cow. Theriogenology, v. 27, n. 2, p. 369 $382,1987$.

PERRY, R.C., CORAH, L.H., KRACOFE, G.H., et al. Endocrine changes in ultrasonography of ovarian function in postpartum suckled beef cows. J Anim Sci, v. 67, p. 332, 1989.

ROBERTS, S.J. Veterinary obstetrics and genital diseases. 3. ed. Ann Arbour: Edward Brothers, 1986, 981 p. 